\title{
PRVI NALAZ AZIJSKE PAMUČNE ŠTITASTE UŠI TAKAHASHIA JAPONICA U HRVATSKOJ
}

\section{THE FIRST RECORD OF THE ASIATIC STRING COTTONY SCALE TAKAHASHIA JAPONICA IN CROATIA}

\author{
Nediljko LANDEKA 1 , Mirela UZELAC ${ }^{2}$, Danijela POLJUHA ${ }^{2}$, Barbara SLADONJA ${ }^{2}$
}

\begin{abstract}
SAŽETAK
Azijska pamučna štitasta uš Takahashia japonica Cockerell (Hemiptera, Coccomorpha, Coccidae), vrsta je porijeklom iz Japana. U Europi je prvi put pronađena 2017. godine u Italiji te 2018. godine u Velikoj Britaniji. U ovom radu dajemo pregled prvog nalaza vrste T. japonica u Hrvatskoj. Prvi nalaz kukca T. japonica uočen je 2019. godine u Puli (Istarska županija, Hrvatska), a vrsta je determinirana u proljeće 2020 godine. Kako bi što učinkovitije prikupili terenske podatke, pokrenuli smo kampanju po načelu ,građani znanstvenici“ pod naslovom: “Traži se neobičan kukac - Takahashia japonica". Poziv za dostavu dojava s lokacijama poslan je svim komunalnim gradskim poduzećima u Istri, javnim ustanovama zaštićenih područja, nevladinim udrugama te je podijeljen u lokalnim novinama i radio postajama. Specifična morfologija ooteka omogućila je lako prepoznavanje ove vrste i osigurala pouzdanost dojava građana. Tijekom kampanje prikupljeno je ukupno sedam dojava u širem središtu grada Pule. Najčešća biljka domaćin bila je Acer sp. i Morus alba L. od kojih su neka stabla pretrpjela značajnu defolijaciju te propadanje krošnje. S obzirom na ograničenu zarazu i relativno mali broj zaraženih stabala opravdano je pokušati provesti potpuno uklanjanje ove vrste. Postupci mjera ranog otkrivanja i brzog iskorjenjivanja invazivnih štetočina u skladu su s Pravilnikom br. 1143/2014 Europskog parlamenta i Vijeća te Europske i Mediteranske Organizacije za Zaštitu Bilja (EPPO). Aktivnosti iskorjenjivanja dogovorene su s gradskim komunalnim poduzećem Herculanea d.o.o. koji je odgovoran za hortikulturu i zaštitu biljaka u gradu Puli.
\end{abstract}

KLJUČNE RIJEČl: prvi nalaz, azijska pamučna štitasta uš (Takahashia japonica), biljni nametnik, invazivna vrsta, rano otkrivanje

\section{UVOD}

\section{INTRODUCTION}

Štitaste uši su mali fitofagni kukci rasprostranjeni na svim kontinentima osim Antarktike, invazivni su i važni biljni nametnici. Do sada je opisano 8194 vrsta štitastih uši iz 50 porodica (Garcia Morales i sur. 2015). Strane štitaste uši čine 30\% ukupne faune štitastih uši u entomofauni u bliskim državama, primjerice u Italiji (Mazzeo i sur. 2014; Pellizzari i Porcelli, 2014). U Hrvatskoj je zabilježeno čak
56 stranih vrsta štitastih uši koje spadaju u osam različitih porodica (Masten Milek i sur. 2016).

Prirodno stanište azijske pamučne štitaste uši Takahashia japonica su zemlje Dalekog istoka: Kina, Indija, Japan i Južna Koreja (Xie i sur. 2006; Garcia Morales i sur. 2015). Do sada su njezini poznati domaćini stabla pripadnika rodova: Acer, Albizia, Alnus, Celtis, Citrus, Cornus, Cydonia, Diospyros, Juglans, Magnolia, Morus, Parthenocissus, Prunus, Pyrus, Robinia, Sophora i Salix. U Europi su do danas

\footnotetext{
${ }^{1}$ dr. sc. Nediljko Landeka, Zavod za javno zdravstvo Istarske županije, Služba za epidemiologiju, Nazorova 23, p.p.192, 52 100 Pula, Hrvatska, e-mail: ddd@@zzjziz.hr ${ }^{2}$ mag. oecol. Mirela Uzelac, dr. sc. Danijela Poljuha, dr. sc. Barbara Sladonja, Institut za poljoprivredu i turizam, Karla Huguesa 8, 52440 Poreč, Hrvatska, e-mail: mirela@iptpo.hr, danijela@iptpo.hr, barbara@iptpo.hr
} 


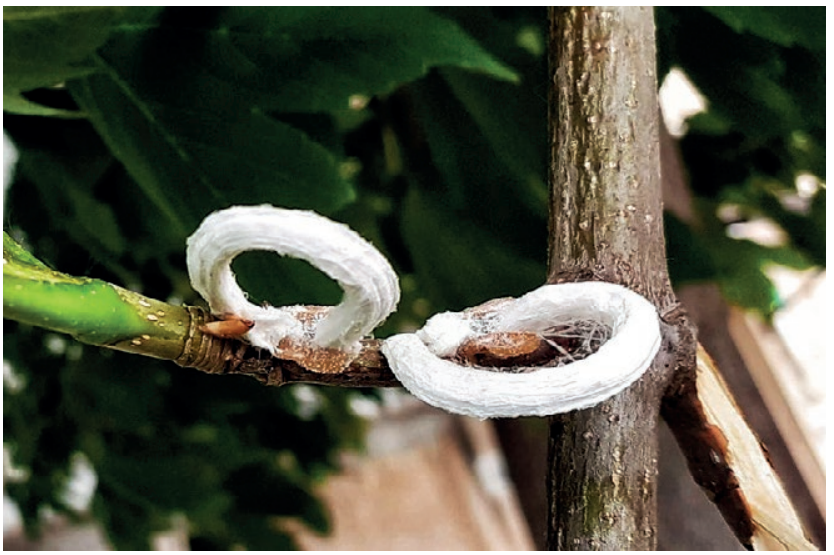

Slika 1. Oooteke azijske pamučne štitaste uši Takahashia japonica na stablu javora (N. Landeka)

Figure 1. Eggsacs of the string cottony scale Takahashia japonica on a maple tree (N. Landeka)

objavljena dva nalaza, jedan u Italiji 2017. godine (Limonta i Pellizzari, 2018) te jedan u Velikoj Britaniji 2018. godine (Tuffen i sur. 2019). Ova vrsta navedena je na listi Europske i mediteranske organizacije za zaštitu bilja važnih stranih biljnih nametnika (EPPO 2020).

Jedinke odraslih ženki su svijetlo smeđe boje, duljine tijela do $7 \mathrm{~mm}$ te širine do $4 \mathrm{~mm}$. Zrele ženke su tamno smeđe, s dubokim brazdama na leđnom dijelu. Svaka ženka proizvodi nitaste bijele voštane ooteke, duljine do $5 \mathrm{~cm}$, koje često oblikuju prstene smještene ispod kukca (Slika 1 i 2). Ooteke su čvrste građe te ostaju pričvršćene na grane i nakon što se jajašca izlegnu. Biologija vrste nije u potpunosti poznata, no zna se da u našim klimatskim uvjetima ona ima jednu generaciju godišnje (Defra Plant Pest Factsheet 2019). Izlijeganje jajašaca se događa se tijekom mjeseca lipnja kada nimfe prelaze na naličje lisne plojke. Krajem ljeta nimfe se vraćaju na grane domaćina gdje prezimljuju u obliku kukuljice. Nimfe se lokalno šire vjetrom. Širenje na veće udaljenosti vjerojatno se događa putem prijenosa zaraženog biljnog materijala.

$\mathrm{U}$ ovom radu predstavljamo prve nalaze vrste T. japonica u Hrvatskoj te opisujemo postupak ranog otkrivanja i brzog iskorjenjivanja invazivne vrste preporučene Uredbom br. 1143/2014 Europskog parlamenta i Vijeća te od strane Europske i mediteranske organizacije za zaštitu bilja (EPPO - European and Mediterranean Plant Protection Organization).

\section{MATERIJALI I METODE MATERIALS AND METHODS}

U proljeće 2019. godine, u Zavod za javno zdravstvo Istarske županije pristigla je prva dojava građana o neobičnim tvorbama na stablu u Puli, no vrsta tada nije bila prepoznata. Slične tvorbe ponovo su uočene u svibnju 2020. na

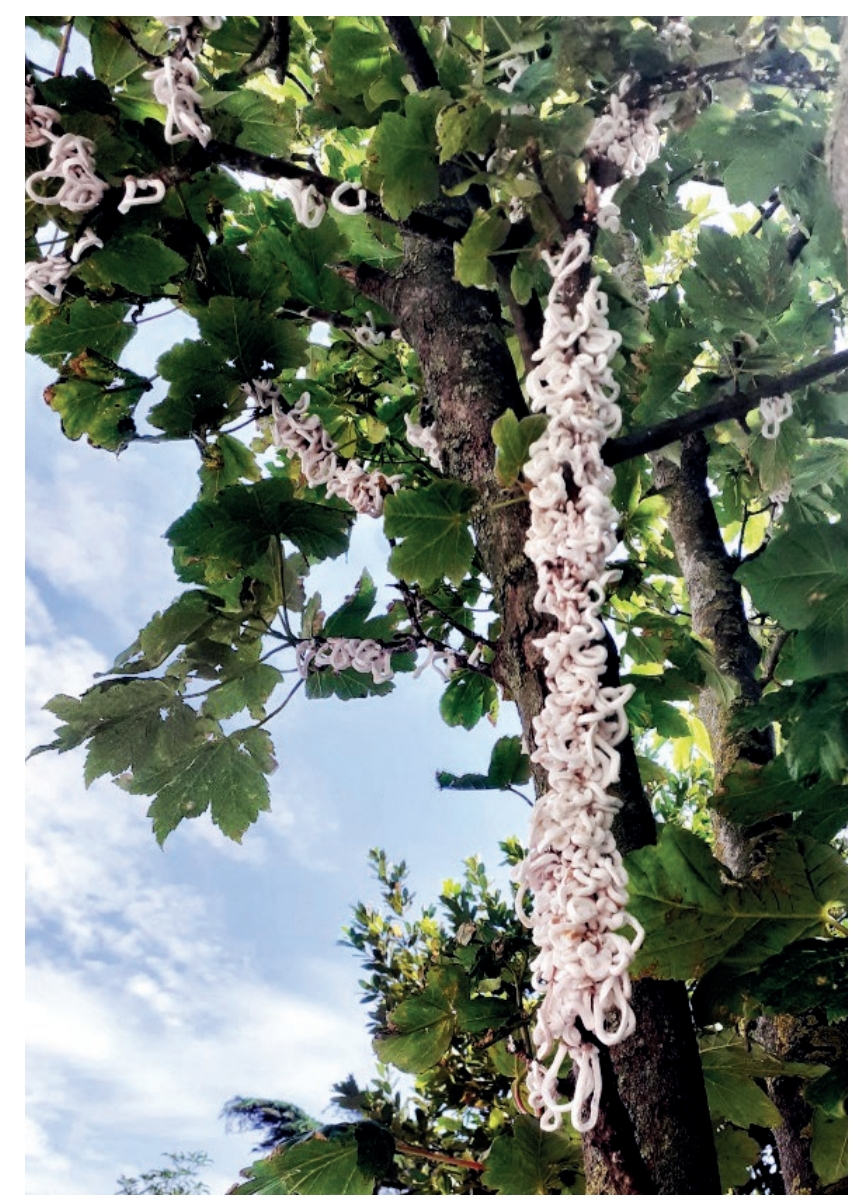

Slika 2. Primjer visoke infestacije na stablu javora (N. Landeka) Figure 2. High infestation example on a maple tree (N. Landeka)

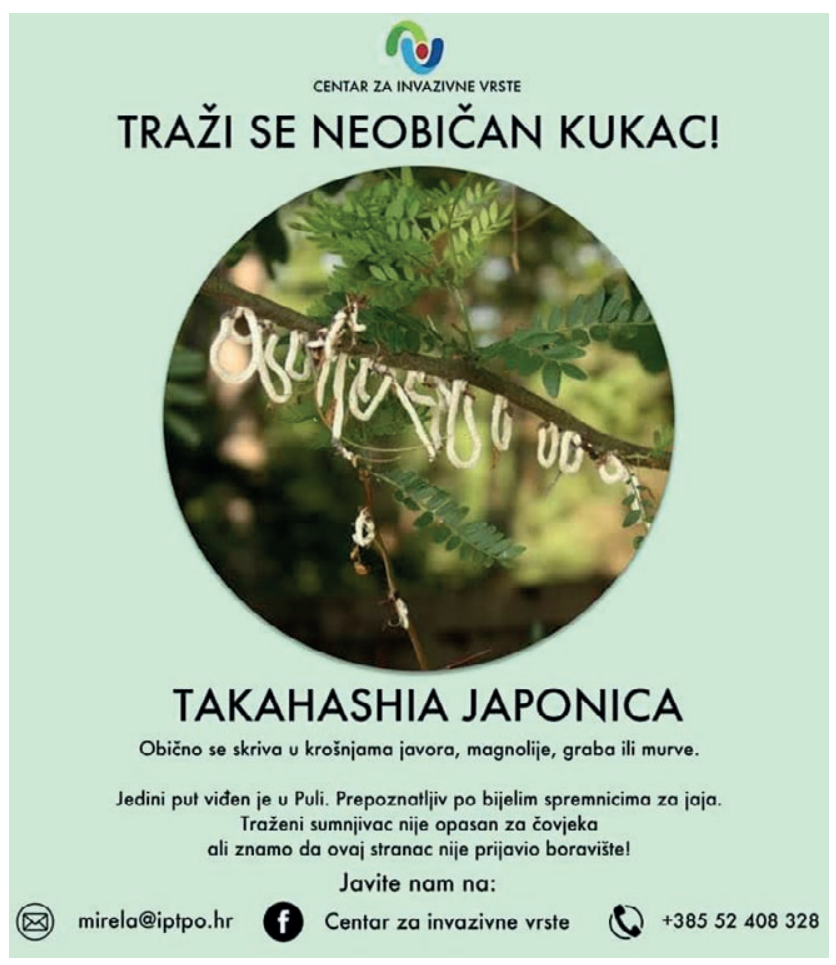

Slika 3. Poziv građanima za dojavu lokacija $T$. japonica

Figure 3. A citizen science campaign - call for citizens 
stablu albicije (Albizia julibrissin Durazz) u središtu Pule. Korištenjem stručne literature, vrstu smo determinirali kao stranu vrstu azijske pamučne štitaste uši Takahashia japonica. Determinaciju vrste potvrdio je dr.sc. Nicola Bressi iz Prirodoslovnog muzeja u Trstu (Italija). Kako bi na brz i učinkovit način prikupili podatke o rasprostranjenosti ove vrste u Istarskoj županiji, pokrenuli smo kampanju po načelu „građani znanstvenici“. Kampanja pod nazivom "Traži se neobičan kukac - Takahashia japonica" sastojala se od fotografije ooteka ove vrste te kratkog popratnog opisnog teksta (Slika 3). Poziv za dostavu dojava s lokacijama poslan je svim komunalnim gradskim poduzećima u Istri (u Odsjek za hortikulturu), Nacionalnom Parku Brijuni i Javnoj ustanovi za upravljanje zaštićenim dijelovima prirode Istarske županije Natura Histrica te udruzi Zelena Istra. S ciljem uključivanja građana Istarske županije u kartiranje, poziv je objavljen u lokalnim tiskovinama, na internetskim portalima te društvenim mrežama Facebook i Instagram. Specifičnost izgleda ooteka omogućila je građanima lako prepoznavanje ove vrste te osigurala pouzdanost njihovih dojava. Svaku dojavu nove lokacije provjerili smo determinacijom vrste na terenu. Uzorak jedinki T. japonica depozitiran je u Prirodoslovnom muzeju Rijeka u entomološkoj zbirci pod inventurnim brojem ENT15000.

\section{REZULTATI I DISKUSIJA RESULTS AND DISCUSSION}

Tijekom dvotjedne kampanje zaprimili smo ukupno dvanaest dojava građana od čega je sedam dojava u užem središtu Pule potvrđeno kao lokacija vrste T. japonica (Tablica 1.). S obzirom da je udaljenost između potvrđenih dojava tek nekoliko stotina metara možemo zaključiti da je areal vrste zasad ograničen (Slika 4.). Prvi determinirani nalaz

Tablica 1. Lokaliteti prvih nalaza azijske pamučne štitaste uši T. japonica u Hrvatskoj

Table 1. Locations of the first records of Asian string cottony scale T. japonica in Croatia

\begin{tabular}{|c|c|c|c|}
\hline Datum & Ulica / Grad & GPS koordinate & Biljka domaćin \\
\hline 18. 5. 2020. & Nazorova ulica 14, Pula & $\begin{array}{l}\text { N } 44.862536 \\
\text { E } 13.849222\end{array}$ & Javor (Acer sp.) \\
\hline 28. 5. 2020. & $\begin{array}{l}\text { Ulica Kašića Miošića 4, } \\
\text { Pula }\end{array}$ & $\begin{array}{l}\text { N } 44.864081 \\
\text { E } 13.848633\end{array}$ & $\begin{array}{l}\text { Murva } \\
\text { (Morus alba L.) }\end{array}$ \\
\hline 28. 5. 2020. & Mutilska ulica 69, Pula & $\begin{array}{l}\text { N } 44.863169 \\
\text { E } 13.858957\end{array}$ & $\begin{array}{l}\text { Albicija (Albizia } \\
\text { julibrissin Durazz) }\end{array}$ \\
\hline 28. 5. 2020. & $\begin{array}{l}\text { Valvazorova ulica } 15, \\
\text { Pula }\end{array}$ & $\begin{array}{l}\text { N } 44.865168 \\
\text { E } 13.855272\end{array}$ & Javor (Acer sp.) \\
\hline 28. 5. 2020. & $\begin{array}{l}\text { Santoriova ulica 22, } \\
\text { Pula }\end{array}$ & $\begin{array}{l}\text { N } 44.866918 \\
\text { E } 13.856612\end{array}$ & Javor (Acer sp.) \\
\hline 2. 6. 2020 . & $\begin{array}{l}\text { Medulinska cesta 183, } \\
\text { Pula }\end{array}$ & $\begin{array}{l}\text { N } 44.859541 \\
\text { E } 13.871450\end{array}$ & $\begin{array}{l}\text { Murva } \\
\text { (Morus alba L.) }\end{array}$ \\
\hline
\end{tabular}

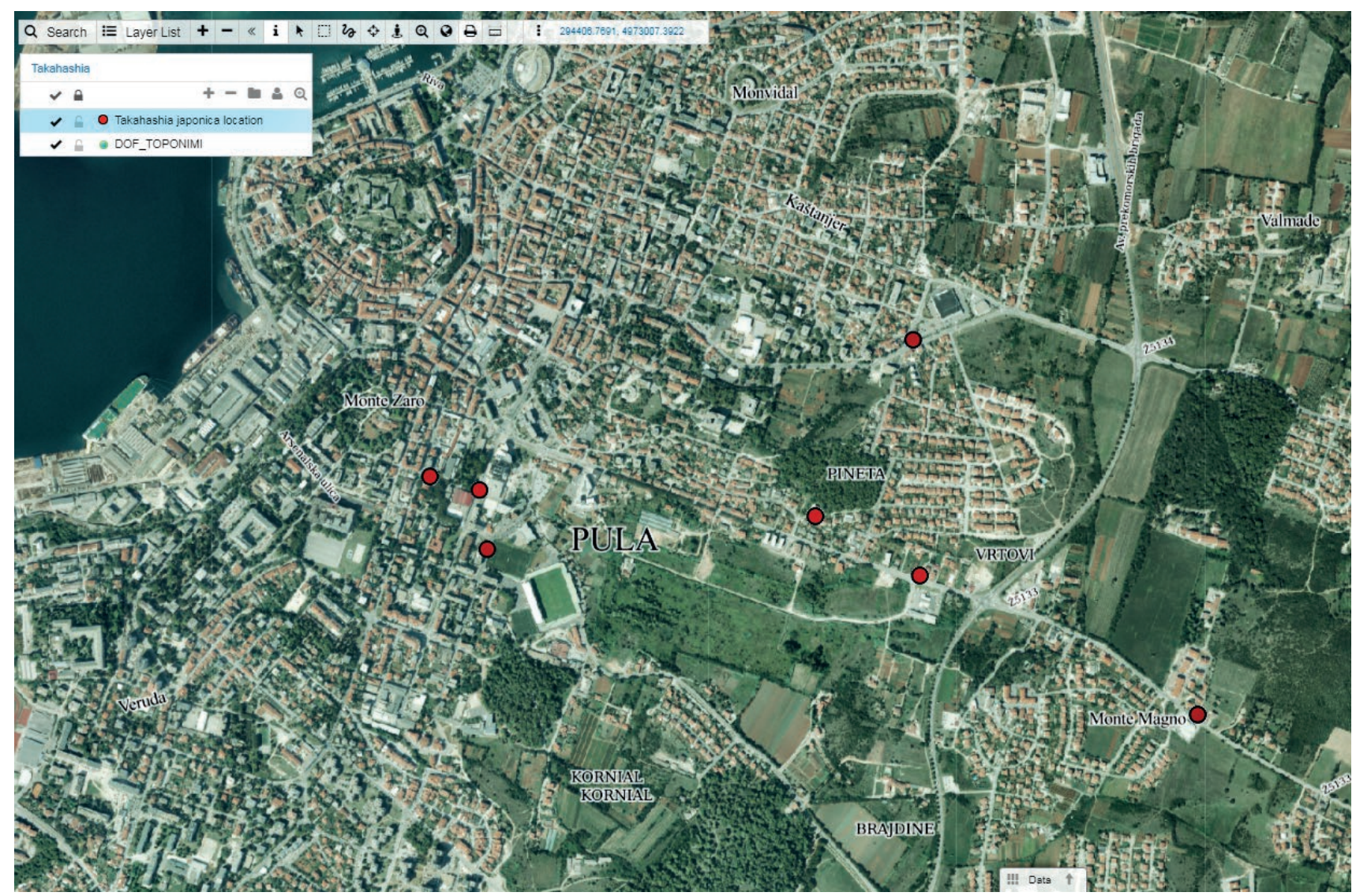

Slika 4. Karta rasprostranjenosti vrste T. japonica u užem središtu Pule

Figure 4. Distribution map of $T$. japonica species in the center of Pula 
bio je 18. svibnja 2020. godine kad su ooteke zamijećene na stablu javora, u ulici Nazorova $14 \mathrm{u}$ Puli. Sve dojave građana proslijeđene su Ministarstvu zaštite okoliša i energetike putem online obrazaca na Portalu o invazivnim vrstama u Republici Hrvatskoj.

Put unosa T. japonica u Hrvatsku nije poznat, no najvjerojatniji način širenja je putem transporta hortikulturnog materijala ili na neki drugi pasivni način.

\section{Negativni učinak vrste $T$. japonica - Negative impact of the species T. japonica}

Ovaj strani nametnik može se smatrati invazivnim, jer zadovoljava uvjete iz definicije biljnih štetnika (Matošević i Pernek 2011). Invazijom u ekosustave, strane štitaste uši utječu na bioraznolikost, uzrokuju štete na samoniklom i uzgojenom bilju te značajne ekonomske gubitke (Masten Milek i sur. 2016).

Ovim istraživanjem uočen je negativan utjecaj T. japonica na biljne domaćine. Usporedbom istog stabla albicije ( $A$. julibrissin) iz srpnja 2018. godine (Slika 5A.) te svibnja 2020. godine (Slika 5B.) zamijećena je značajna defolijacija i propadanje stabla.
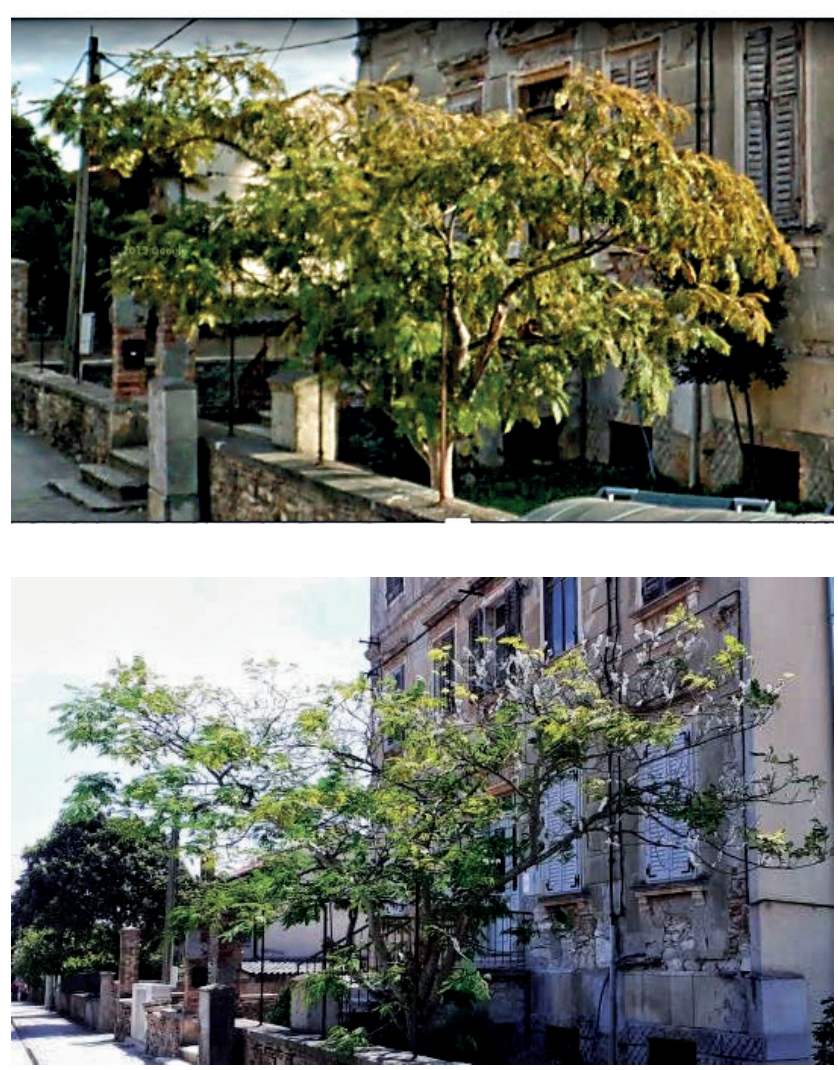

Slika 5. A) Kineska mimoza srpanj 2018. godine i B) isto stablo zaraženo azijskom pamučnom štitastom uši Takahashia japonica u svibnju 2020. (preuzeto: 2. 6. 2020.; Street view)

Figure 5. A) Chinese silk tree in July 2018 and B) the same tree infected by the Asian string cottony scale Takahashia japonica in May 2020 (retrieved: 2. 6.2020.; Street view)

\section{Upravljanje invazivnom vrstom $T$. japonica -} Management of the invasive species T. japonica

Temeljni dokument za upravljanje invazivnim vrstama u Republici Hrvatskoj je Zakon o sprječavanju unošenja i širenja stranih te invazivnih stranih vrsta i upravljanju njima (NN 15/18). Ovim se Zakonom utvrđuje okvir za provedbu odredbi važećih EU dokumenata iz područja invazivnih vrsta kao što je Uredba (EU) br. 1143/2014. U članku 24. Uredbe o sprječavanju i upravljanju unošenja i širenja invazivnih stranih vrsta navedeno je da su nakon unošenja invazivne strane vrste, mjere ranog otkrivanja i brzog iskorjenjivanja od ključne važnosti za sprječavanje njezinog naseljavanja i širenja. Često je najučinkovitiji i troškovno najisplativiji odgovor iskorjenjivanje populacije $\mathrm{u}$ što kraćem roku, dok je broj jedinki još ograničen. S obzirom na ograničenu zarazu i relativno mali broj zaraženih stabala, opravdano je pokušati provesti potpuno uklanjanje vrste. $S$ tim ciljem dogovorene su aktivnosti s gradskim komunalnim poduzećem Herculanea d.o.o. koje je nadležno za hortikulturu i zaštitu bilja na području grada Pule. Izdana je preporuka uklanjanja zaraženih grana, njihovo spaljivanje te tretiranje drveća insekticidom.

Potrebno je aktivno pratiti moguće širenje vrste i njezinu invazivnost te obratiti posebnu pozornost na odabir biljke domaćina. S obzirom da je vrsta izvan svog prirodnog areala moguće su promjene domaćina te promjene u obrascima ponašanja ove vrste. Ukoliko potpuno uklanjanje vrste ne bude učinkovito, u planu je nastavak laboratorijskih i terenskih istraživanja ove vrste s ciljem izrade procjene širenja areala.

\section{ZAHVALA \\ ACKNOWLEDGEMENTS}

Zahvaljujemo uključenim ustanovama i udrugama na sudjelovanju u kampanji te svim zainteresiranim i motiviranim građanima koji su se odazvali na poziv za suradnju te dali svoj doprinos u determinaciji i izradi vrijedne i pouzdane baze podataka. Zahvaljujemo i prof. dr. Borisu Hrašovecu, dr. sc. Marinu Kirinčiću te mr. sc. Romanu Ozimec na svojem doprinosu.

\section{LITERATURA}

\section{REFERENCES}

- EPPO 2020. EPPO Global Database (available online). Pristupano na https://gd.eppo.int (2.06.2020.)

- Defra. Plant Pest Factsheet. Cotton stringy scale insect Takahashia japonica, 2019, 3 pp. (available online). Pristupano na https://planthealthportal.defra.gov.uk/assets/factsheets/Takahashia-japonica-Defra-PP-Factsheet-Mar-2019.pdf (2.06.2020.)

- Garcìa Morales, M., B.D. Denno, D.R. Miller, G.L. Miller, Y. Ben-Dov, N.B. Hardy, 2016.: ScaleNet: a literature-based model 
of scale insect biology and systematics. Database-Oxford Vol. 2016: $1 .-5$.

- Limonta, L., Pellizzari, G., 2018: First record of the string cottony scale Takahashia japonica in Europe and its establishment in Northern Italy. Bulletin of Insectology 71 (1): 159.-160.

- Masten Milek, T., Šimala,M., Pintar, M., 2016: The dynamics of introduction of alien scale insects (Hemiptera: Coccoidea) into Croatia. Bulletin OEPP/EPPO Bulletin 201646 (2): 298.-304.

- Mazzeo, G., Longo, S., Pellizzari, G., Porcelli, F., Suma, P., Russo A., 2014: Exotic scale insects (Coccoidea) on ornamental plants in Italy: a never ending story.- Acta Zoologica Bulgarica, Supplementum 6: 55-61.
- Pellizzari, G., Porcelli, F., 2014: Alien scale insects (Hemiptera Coccoidea) in European and Mediterranean countries: the fate of new and old introduction. Phytoparasitica. 42: 713-721.

- Tuffen, M., Salisbury, A., Malumphy, C., 2019: Cotton stringy scale insect, Takahashia japonica (Hemiptera: Coccidae), new to Britain. Br. J. Ent. Nat. Hist. 32: 1.-4.

- Uredba (EU) Europskog parlamenta i vijeća od 22. listopada 2014. o sprječavanju i upravljanju unošenja i širenja invazivnih stranih vrsta, br. 1143/2014

- Xie, Y. P., Xue, J. L., Zheng, L., 2006: Wax secretions of soft scale insects their ultrastructure \& chemical composition.- China Forestry Publishing House, Beijing, China

\section{SUMIMARY}

The Asiatic string cottony scale Takahashia japonica Cockerell (Hemiptera, Coccomorpha, Coccidae) is a species native to Japan. The first record in Europe was observed in Italy in 2017 and again in UK in 2018. In this paper, we provide an overview of the first record of T. japonica in Croatia. First appearance of T. japonica was in 2019 in Pula (Istrian County, Croatia) but the species was determined in spring 2020. In order to collect the field data as efficiently as possible we launched a citizen scientist campaign under title: "A search for an insect - Takahashia japonica". The campaign was shared to city utility companies in Istria, public institutions of protected areas, NGOs, local newspapers and radio stations. The specific morphology of the eggsacs enabled easy recognition of this species and ensured the accuracy of citizens' reports. During the campaign we have collected in total seven reports in the city of Pula. The most common host plant of T. japonica was Acer sp. and Morus alba L. some of which have suffered significant defoliation and tree decay. Given the limited infestation and the relatively small number of infected trees, next step is to carry out a complete eradication of the species. The procedures of early detection measures and rapid eradication of invasive pest is in accordance to Regulation no. 1143/2014 of the European Parliament and the Council and by the European and Mediterranean Plant Protection Organization (EPPO). In the end, eradication activities have been agreed with the city utility company Herculanea d.o.o. which is responsible for horticulture and plant protection in the city of Pula. 